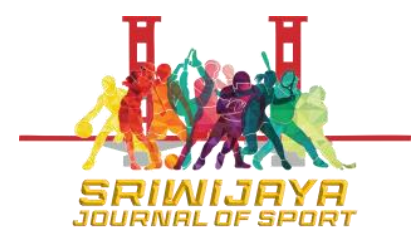

Sriwijaya Journal of Sport

Volume 1, Nomor 1, Oktober 2021: 20-28

http://ejournal.fkip.unsri.ac.id/index.php/sjs e-ISSN 2808-5299

p-ISSN 2808-5701

\title{
Survei aktivitas belajar anak tunagrahita ringan dalam pembelajaran pendidikan jasmani
}

\section{Survey of learning activities for mild mentally retarded children in physical education learning}

\section{Ayu Nida Nur Rahmania ${ }^{*},{ }^{,}$, Basuki ${ }^{1}$}

${ }^{1}$ Pendidikan Jasmani, STKIP PGRI Jombang, Jombang, Indonesia

${ }^{*}$ Corresponding Author

\begin{abstract}
Abstrak
Penelitian ini bertujuan untuk mengetahui keaktifan belajar peserta didik tunagrahita ringan dalam pembelajaran pendidikan jasmani adaptif pada masa new normal. Metode survei dilakukan dalam penelitian ini untuk mengetahui data keaktifan peserta didik. Teknik pengumpulan data menggunakan instrumen penilaian berupa checklist dengan cara observasi pembelajaran. Hasil penelitian ini menunjukkan bahwa observasi yang dilakukan sebanyak dua kali pengamatan diperoleh hasil persentase tertinggi yaitu $56,25 \%$ peserta didik yang aktif dalam proses pembelajaran dengan indikator selalu aktif mendapatkan persentase 33,25\%, kadang aktif 19,50\%, dan tidak aktif sebesar 3,50\%. Berdasarkan hasil penelitian yang telah dilakukan, diperoleh kesimpulan bahwa tingkat keaktifan peserta didik tunagrahita dalam mengikuti pembelajaran pendidikan jasmani adaptif di SLBN Jombang dapat dikatakan aktif.
\end{abstract}

Kata Kunci: Aktivitas; Pembelajaran; Tunagrahita; Adaptif.

\begin{abstract}
This study aims to determine the learning activity of mild mentally retarded students in learning adaptive physical education in the new normal period. The survey method was carried out in this study to find out the active data of students. The data collection technique used an assessment instrument in the form of a checklist by means of learning observation. The results of this study indicate that observations were made twice, the highest percentage was $56.25 \%$ of students who were active in the learning process with indicators always active getting a percentage of $33.25 \%$, sometimes active $19.50 \%$, and inactive at $3.50 \%$. Based on the results of the research that has been done, it can be concluded that the level of activity of mentally retarded students in participating in adaptive physical education learning at SLBN Jombang can be said to be active.
\end{abstract}

Keywords: Activity; Learning; Mentally-disabled; Adaptive.

Received: 29 September 2021; Revised: 9 October 2021; Accepted: 22 October 2021

Corresponding author: Ayu Nida Nur Rahmania, Jl. Pattimura III/20, Jombang, Jawa Timur

Email: ayunidanr@gmail.com

\section{PENDAHULUAN}

Tidak ada manusia sempurna yang diciptakan oleh Tuhan di dunia ini, tujuannya adalah agar sesama umat manusia di dunia bisa membantu 
melengkapi tidak kesempurnaan itu. Ada kalanya manusia diciptakan dengan kondisi kejiwaan yang baik namun dengan kondisi cacat fisik dan ada manusia diciptakkan fisik yang baik tapi mengalami cacat kejiwaan. Pada zaman ini manusia diharuskan untuk terus mengikuti dan beradaptasi terhadap perkembangan dunia yang semakin kompetitif agar tetap dapat mempertahankan kelangsungan hidupnya, tapi kita terkadang kurang menyadari bahwa ada sebagian manusia yang mengalami keterbatasan fisik ataupun mental sehingga tidak mampu mengimbangi perkembangan dunia tersebut dan perlu mendapat bantuan yakni Anak Berkebutuhan Khusus (ABK) (Basuni, 2012).

Terdapat beberapa macam kecacatan pada anak berkebutuhan khusus salah satunya adalah penyandang mental atau sering disebut sebagai anak tunagrahita. Tunagrahita adalah individu yang memiliki intelegensi yang signifikan berada dibawah rata-rata dan disertai dengan ketidakmampuan dalam adaptasi perilaku yang muncul dalam masa perkembangan (Arifin \& Kumaat, 2016). Dengan kondisi tersebut maka anak tunagrahita perlu diperhatikan bagaimana dia mendapat pendidikan layak sesuai kebutuhan mereka agar dapat mengembangkan kecakapan fisik, mental, emosional dan sosialnya.

Tujuan untuk pertumbuhan dan perkembangan kognitif, afektif, psikomotor dan fisik anak didik melalui kegiatan jasmani, maka pendidikan jasmani dalam sebuah sistem pendidikan menjadi bagian yang penting. (Wuest \& Bucher, 2015) mengatakan pendidikan jasmani menjadi salah satu media untuk membantu tercapainya tujuan pendidikan secara keseluruhan serta diharapkan dapat berkontribusi positif terhadap peningkatan Indeks Pembangunan Manusia (Human Index Development). Lalu dikuatkan oleh pendapat (Ginanjar, 2019) pendidikan jasmani adalah suatu proses pemebelajaran melalui aktifitas jasmani yang didesain untuk meningkatkan kebugaran jasmani, mengembangkan keterampilan motorik, pengetahuan dan perilaku hidup sehat dan aktif, sikap sportif dan kecerdasan emosi. Pendidikan jasmani menjadi mata pelajaran umum maupun khusus kepada jenjang pendidikan dasar (SD) sampai dengan 
jenjang pendidikan menengan (SMP) dan atas (SMA) (Bayu \& Andrianto, 2014).

Pendidikan jasmani adaptif adalah pendidikan jasmani untuk anak berkebutuhan khusus agar mereka dapat melakukan aktivitas yang sama dengan anak normal secara aman dan sesuai dengan kebutuhan belajar mereka. Tujuan pendidikan jasmani adaptif yakni untuk pertumbuhan dan perkembangan individu anak berkebutuhan khusus agar mereka dapat menjadi pribadi yang mandiri secara bertahap dengan pengawasan dan pendampingan khusus (Inarta \& Aziz, 2020). Dalam sebuah pembelajaran, keaktifan sangatlah penting untuk dapat menunjang kegiatan belajar mengajar dapat berjalan dengan baik dan menyenangkan apalagi untuk anak yang berkebutuhan khusus. Pembelajaran pendidikan jasmani adaptif, keaktifan menjadi sebuah tujuan yang harus dicapai, keaktifan disini sendiri yang dimaksud adalah kegiatan yang bersifat fisik maupun mental, yaitu berbuat dan berpikir sebagai suatu rangkaian yang tidak dapat dipisahkan (Basuni, 2012).

Anak dikatakan aktif saat kegiatan pembelajaran pendidikan jasmani adaptif berlangsung bila mengikuti instruksi dari guru. Ketrampilan gerak yang mereka miliki sejak dini menjadi sebuah patokan bagaimana keaktifan penampilan geraknya saat menginjak usia remaja, lalu menjadi sangat penting saat beranjak dewasa dan usia tua. Keaktifan juga digunakan sebagai penilaian dalam sebuah pembelajaran pendidikan jasmani adaptif itu sendiri, dimana anak yang aktif maka akan bergerak dan menimbulkan perasaan yang bahagia serta menyenangkan (Arifin \& Kumaat, 2016). Penelitian ini bertujuan untuk menilai tingkat aktifitas peserta didik dengan kategori tunagrahita ringan dalam mengikuti pembelajaran pendidikan jasmani. Hal ini dilakukan untuk dapat melihat apakah peserta didik dengan tingkat tunagrahita ringan masih dapat mengikuti instruksi dari guru pendidikan jasmani. 


\section{METODE}

Jenis penelitian yang digunakan dalam penelitian ini adalah deskriptif kuantitatif dengan metode survei, sedangkan teknik pengambilan data yang digunakan menggunakan instrumen penilaian berupa checklist. Metode deskriptif adalah metode yang digunakan untuk menggambarkan atau menganalisis suatu hasil penelitian tetapi tidak digunakan untuk membuat kesimpulan yang lebih luas (Sugiyono, 2017). Populasi dalam penelitian ini adalah peserta didik SLBN Jombang dalam kategori C (Tunagrahita) yang berjumlah 34 anak. Dalam penentuan sampel, digunakan teknik purposive sampling atau pengambilan sampel berdasarkan pertimbangan khusus (Fraenkel et al., 2012), antara lain: 1) peserta didik SLBN Jombang; 2) peserta didik tunagrahita dan tidak berkebutuhan ganda; dan 3) sehat jasmani (tidak sakit) pada saat penelitian. Data yang diperoleh kemudian dianalisis dengan menggunakan analisis data perhitungan statistik deskriptif persentase, yaitu dengan cara mengadakan persentase dan penyebaran serta memberikan penafsiran yang diperoleh atas dasar persentase tersebut (Sudjana, 2011). Setelah data deskriptif persentase yang berupa data statistik telah diketahui kemudian digolongkan atau diklasifikasikan ke dalam kriteria yang telah ditentukan seperti tampak pada tabel 1 .

Tabel 1. Kriteria Penilaian Peserta Didik

\begin{tabular}{ccc}
\hline Interval Skor & Interval Persentase & Kriteria \\
\hline $97,75-120$ & $81,26 \%-100 \%$ & Selalu Aktif \\
$75-97,5$ & $62,51 \%-81,25 \%$ & Sering Aktif \\
$52,5-75$ & $43,76 \%-62,50 \%$ & Kadang-Kadang Aktif \\
$30-52,5$ & $25 \%-43,75 \%$ & Tidak Pernah Aktif \\
\hline
\end{tabular}

\section{HASIL}

Berdasarkan pengamatan pertama yang telah dilakukan peneliti pada tanggal 21 Juni 2021, tingkat keaktifan peserta didik tunagrahita dalam mengikuti pembelajaran pendidikan jasmani di SLBN Jombang didapat persentase selalu aktif $(31,25 \%)$, sering aktif $(50,00 \%)$, kadang aktif $(12,50 \%)$, dan tidak pernah aktif $(6,25 \%)$.

Tabel 2. Hasil Pengamatan Keaktifan Peserta Didik Pertemuan Pertama 


\begin{tabular}{ccc}
\hline Kriteria Keaktifan & Frekuensi & Persentase \\
\hline Selalu & 5 & $31,25 \%$ \\
Sering & 8 & $50.05 \%$ \\
Kadang & 2 & $12,50 \%$ \\
Tidakpernah & 1 & $6,25 \%$ \\
\hline Total & $\mathbf{1 6}$ & $\mathbf{1 0 0} \%$ \\
\hline
\end{tabular}

Berdasarkan pengamatan kedua yang telah dilakukan peneliti pada tanggal 12 Juli 2021, tingkat keaktifan peserta didik tunagrahita dalam mengikuti pembelajaran pendidikan jasmani di SLBN Jombang didapat persentase selalu aktif (25\%), sering aktif $(62,50 \%)$, kadang aktif $(12,50 \%)$, dan tidak pernah aktif $(0 \%)$.

Tabel 3. Hasil Pengamatan Keaktifan Peserta Didik Pertemuan Pertama

\begin{tabular}{ccc}
\hline Kriteria Keaktifan & Frekuensi & Persentase \\
\hline Selalu & 4 & $25,00 \%$ \\
Sering & 10 & $62,50 \%$ \\
Kadang & 2 & $12,50 \%$ \\
Tidakpernah & 0 & $0 \%$ \\
\hline Total & $\mathbf{1 6}$ & $\mathbf{1 0 0} \%$ \\
\hline
\end{tabular}

Hasil penelitian yang diperoleh meenunjukkan tingkat keaktifan peserta didik tunagrahita dalam mengikuti pembelajaran jasmani adaptif di SLBN Jombang dapat dikatakan anak sering aktif dengan memperoleh ratarata tertinggi yaitu 56,25\% dalam dua kali penelitian, sedangkan untuk kategori selalu aktif memperoleh rata-rata $28,2 \%$, kadang aktif $12,50 \%$, tidak aktif 3,2\%. Sampel yang digunakan dalam penelitian sebanyak 16 peserta didik tunagrahita dari SLBN Jombang. Hasil dari penelitian didapat melalui pengamatan sebanyak dua kali yang dilakukan peneliti dengan menggunakanan lembar checklist yang terdiri dari empat indikator dengan rentang nilai 1-4. Hasil tersebut membuktikan bahwa pembelajaran yang diberikan oleh guru kepada peserta didik sudah menarik dan dapat menyerap pembelajaran dengan baik. Kesimpulan tersebut dibuktikan dengan kriteria "sering aktif" berada satu tingkat diatas kriteria "selalu aktif" yang berarti pembelajaran yang diberikan sudah baik dan menarik.

\section{PEMBAHASAN}

Tujuan peneliti melakukan pengamatan sebanyak dua kali adalah untuk mencari hasil secara optimal, karena keaktifan anak dalam 
pembelajaran banyak sekali faktor yang mempengaruhinya, diantaranya minat anak akan materi yang disampaikan berbeda-beda. Maka dengan dua kali pengamatan diharapkan peneliti agar mendapatkan data atau hasil secara baik. Berdasarkan dua kali pengamatan yang dilakukan dan memperoleh data yang ada dapat ditarik kesimpulan bahwa tingkat keaktifan peserta didik tunagrahita di SLBN Jombang dalam mengikuti pembelajaran pendidikan jasmani adaptif dapat dikatakan sering aktif. Hal tersebut dapat terjadi karena beberapa faktor yang mempengaruhi, yaitu faktor dari dalam diri anak tersebut (internal) dan faktor dari luar (eksternal). Faktor internal dapat meliputi kondisi biologis, kondisi emosional, dan tingkat perkembangan yang dimiliki.

Anak tunagrahita juga lemah dalam berfikir, sehingga dalam menangkap informasi sedikit terlambat. Selain itu minat dan antusias anak dalam mengikuti pembelajaran tergantung pada kualitas materi pembelajaran yang telah disediakan oleh guru. Adapun faktor eksternal dapat meliputi dukungan dari keluarga, kondisi sosial ekonomi, kelompok sosial dan sekolah. Keaktifan peserta didik saat pembelajaran berbeda akan setiap tingkat ketunaan yang dimiliki peserta didik. Peserta didik dengan ketunaan grahita ringan misalnya, peserta didik masih dapat mengikuti pembelajaran dengan baik, peserta didik masih mau mendengarkan, dan melakukan apa yang diperintahkan oleh guru walaupun terkadang masih sering bermain dengan temannya, sedangkan peserta didik tunagrahita kategori sedang lebih banyak pasif atau berdiam diri saja dan masih bingung apa yang di instruksikan oleh gurunya.

Guru PLB yang tidak memiliki ilmu dalam bidang penjas tentang bagaimana cara mengajar penjas yang baik, inovatif dan menarik secara terpaksa juga harus mengajar karena tuntutan keadaan (Louk \& Sukoco, 2016). Maka dari itu guru mengalami kelemahan dalam mengelola kelas yang ada. Pembelajaran pendidikan jasmani di SLBN Jombang sendiri memiliki sistem kelas pararel, yaitu penggabungan beberapa kelas dalam satu pertemuan tetapi terdapat perubahan sistem pembelajaran menjadi 
lebih diperkecil dikarenakan adanya pandemi Covid-19 maka jumlah peserta didik dibatasi tidak boleh membuat kelompk kelas berskala besar.

Pembelajaran pendidikan jasmani dilaksanakan setiap hari dimulai hari senin-sabtu. Tujuan sekolah membuat jadwal setiap hari tidak lain karena ingin memperingan dan memudahkan dalam proses pembelajaran, karena pada era new normal terdapat pembatasan anak yang masuk sekolah sehingga dilakukan secara bergiliran dengan ini guru mampu mengelola kelas karena bisa terfokus pada peserta didik di bidang mengajar pendidikan jasmani, sehingga mampu menciptakan pembelajaran yang kreatif dan inovatif (Indardi, 2015). Permasalahan yang didapat adalah sulitnya mengatur peserta didik untuk bisa menerapkan pembiasaan baru yakni menerapkan protokol kesehatan pada saat peserta didik melakukan pembelajaran. Tetapi peserta didik juga sangat antusias dalam melakukan pembelajaran dikarenakan setelah mengalami libur panjang akibat tidak dapat masuk sekolah karena pandemi Covid-19 mereka sangat bersemangat. Sama seperti peserta didik normal pada umumnya, peserta didik tunagrahita juga menyukai jenis pembelajaran permainan yang sudah dimodifikasi baik peraturan maupun alatnya atau juga bisa dengan permainan tradisional (Ardiyanto \& Sukoco, 2014). Selain itu dalam proses pembelajaran pendidikan jasmani guru juga tidak lupa memberikan reward kepada peserta didik yang berani aktif mengajukan pertanyaan ataupun menjawab pertanyaan dan melukakan intruksi dari guru (Maulidiyah, 2020).

\section{KESIMPULAN}

Tingkat keaktifan peserta didik tunagrahita dalam mengikuti pembelajaran pendidikan jasmani adaptif di SLBN Jombang 2021 dapat dikatakan sering aktif. Hal ini menunjukkan bahwa, peserta didik yang mengalami tunagrahita ringan tidak terpengaruh dengan adanya pembatasan peserta didik yang mengikuti pembeljaran secara tatap muka maupun online. Karena pada dasarnya mereka menyukai aktivtas gerak. 


\section{KONTRIBUSI PENULIS}

Author 1: Writing; Review \& Editing. Author 2: Methodology; Validating.

\section{DAFTAR PUSTAKA}

Ardiyanto, A., \& Sukoco, P. (2014). Pengembangan Model Pembelajaran Berbasis Permainan Tradisional Untuk Meningkatkan Kemampuan Motorik Kasar Anak Tunagrahita Ringan. Jurnal Keolahragaan, 2(2), 119-129. https://doi.org/10.21831/jk.v2i2.2608

Arifin, M. Z., \& Kumaat, N. A. (2016). Pengaruh Modifikasi Permainan Lempar Tangkap Bola Terhadap Koordinasi Gerak Manipulatif Anak Tunagrahita Ringan Siswa Smplb-C Alpha Kumara Wardhana II Surabaya. Jurnal Kesehatan Olahraga, 5(3). https://jurnalmahasiswa.unesa.ac.id/index.php/7/article/view/17788

Basuni, M. (2012). Pembelajaran Bina Diri Pada Anak Tunagrahita Ringan. Jpk: Jurnal Pendidikan Khusus, 9(1). https://doi.org/10.21831/jpk.v9i1.6725

Bayu, W. I., \& Andrianto, J. R. (2014). Profil Pendidikan Jasmani, Olahraga, Dan Kesehatan Pada Tingkat Satuan Pendidikan Sekolah Menengah Atas Se-Kabupaten Jombang Tahun 2016. Bravo's Jurnal, 2(3), 89-97. https://ejournal.stkipjb.ac.id/index.php/penjas/article/view/442/330

Fraenkel, J. R., Wallen, N. E., \& Hyun, H. (2012). How to Design and Evaluate Research in Education. McGraw-Hill Education.

Ginanjar, A. (2019). Implementasi Praktis Sport Education Model. Program Studi Pendidikan Jasmani, Kesehatan, dan Rekreasi, STKIP Nahdatul Ulama Indramayu.

Inarta, G. U., \& Aziz, I. (2020). Pelaksanaan Pembelajaran Pendidikan Jasmani pada Anak Berkebutuhan Khusus di SLB YPPLB kota Padang. Jurnal Patriot, 2(1), 336-344. https://doi.org/10.24036/patriot.v2i1.532

Indardi, N. (2015). Pengulangan Teknik Permainan Kasti Terhadap Peningkatan Kemampuan Motorik Kasar Anak Tunagrahita Ringan. Journal of Physical Education Health and Sport, 2(1), 44-49. https://doi.org/10.15294/jpehs.v2i1.3942

Louk, M. J. H., \& Sukoco, P. (2016). Pengembangan media audio visual dalam pembelajaran keterampilan motorik kasar pada anak tunagrahita ringan. Jurnal Keolahragaan, 4(1), 24. https://doi.org/10.21831/jk.v4i1.8132

Maulidiyah, F. N. (2020). Media Pembelajaran Multimedia Interaktif Untuk Anak Tunagrahita Ringan. Jurnal Pendidikan, 29(2), 93-100. https://doi.org/10.32585/jp.v29i2.647

Sudjana. (2011). Metode Statistika. Tarsito.

Sugiyono. (2017). Metode Penelitian Pendidikan (Pendekatan Kuatitatif, Kualitatif, dan $R \& D)$. Alfabeta. 
Wuest, D., \& Bucher, C. A. (2015). Foundations of Physical Education, Exercise Science, and Sport (18th ed.). In McGraw-Hill Education (19th Editi). McGraw-Hill Education. 